\title{
Urinary Neopterin as Marker for Disease Activity in Children and Adolescents with Crohn's Disease
}

\author{
Gerhard Granditsch"), Dietmar Fuchs's), Arno Hausen ${ }^{2)}$, Gilbert Reibnegger ${ }^{2)}$, Ernst R. Werner ${ }^{2)}$, Gabriele \\ Werner-Felmayer ${ }^{2)}$, and Helmut Wachter ${ }^{2)}$ 3) \\ 1) Kinderklinik, Universität, Währinger Gürtel 18-20, A-1090 Wien, Austria \\ 2) Institut für Medizinische Chemie und Biochemie, Universität, Fritz-Pregl-Str. 3, A-6020 Innsbruck, Austria
}

(Received October 1989)

\begin{abstract}
Summary
Elevated production and excretion of neopterin indicate activation of cell-mediated immunity, since neopterin is produced in large quantities by human macrophages after stimulation with interferon gamma. In 21 patients, aged 9 to 19 years, with Crohn's disease, urinary neopterin was measured on a total of 135 consecutive followup visits. Additionally, a large panel of anamnestic, clinical and laboratory data were obtained at every visit. Both the first visit data set ( 21 records) and the complete data set (135 records) were analyzed separately. As was previously demonstrated in adults with Crohn's disease, neopterin excretion proved to be strongly correlated with overall rating of disease activity, and also with separate anamnestic, clinical and laboratory activity scores. Multiple regression analysis demonstrated that neopterin provides statistically independent information. Thus, measurement of neopterin concentrations as a marker for activation of cellular immune phenomena could aid in the monitoring of pediatric and juvenile Crohn's disease.
\end{abstract}

\section{Introduction}

The etiology of Crohn's disease remains unknown. Various immunological phenomena have been observed, appearing with active disease and subsiding with its quiescence $(1,2)$. Although the data are partly conflicting, changes of immunoregulatory cell activity $(3-5)$ and of humoral and cell-mediated effector systems $(6,7)$ provide evidence for the existence of (probably secondary) immune mechanisms in the course of this disease. One or several primary stimuli appear to set in motion the destructive capabilities of the immune system, with the adverse effects directed against the intestine (8).

Human macrophages produce and secrete large amounts of 6D-erythro-neopterin upon stimulation with interferon gamma (9). Thus, measurement of neopterin in various body fluids is of considerable clinical interest since the concentrations of this pterin

3) Author to whom correspondence should be addressed. provide accurate and sensitive information on the activation state of the cell-mediated immunity. In a great variety of diseases which have in common involvement of cellular immune activation, neopterin measurement has been successfully used $(10,11)$.

In adults with Crohn's disease, neopterin concentrations in urine have been described to sensitively reflect clinical activity of the disease (12). By multivariate statistical techniques, a very simple triple-parametric activity index (referred to here as "Innsbruck index") has been constructed (13) allowing activity monitoring with similar precision as the much more complicated 8-parametric Crohn's disease activity index CDAI (14). The Innsbruck index consists of a linear combination of urinary neopterin concentration, weekly number of liquid or very soft stools, and hematocrit.

The aim of the present study was to investigate the suitability of urinary neopterin as a marker for Crohn's disease activity in children and adolescents. In addition, the value of the Innsbruck index for activity monitoring in these patients was studied. 


\section{Patients and Methods}

Twenty-one consecutive patients of the Children's Hospital of the University of Vienna, Austria, were included in the study. At their first visit included in this investigation, the 15 boys and 6 girls were 9 to 19 years old (mean age 15.5 years). Follow-up time was 1 to 43 months with a mean of 19 months. On average, 6 follow-up investigations per patient were included, with a range from 1 (one very recently diagnosed patient) to 14 visits.

A large number of anamnestic, clinical and laboratory data were collected at each visit:

At each check-up, patients provided questionnaires about the previous week regarding general condition (expressed as a rating score ranging from $1=$ excellent to 4 = bad), number of days absent from school, number of normal, diarrheal and bloody stools, number of nights with interrupted sleep, number of attacks of abdominal pain and, finally, body temperature elevations.

Data documented during clinical examination included body height and weight, weight difference since previous visit, palpability and size of an abdominal mass, tenderness of the abdomen, anal lesions, and other extraintestinal manifestations, e. g., fistulae, abscesses, arthralgia or erythema nodosum.

A venous blood sample was examined by the usual routine procedures for erythrocyte sedimentation rate (ESR), hemoglobin, hematocrit, leukocyte count, band-form and polymorphonuclear neutrophils, platelet count, total serum protein, albumin, alpha-2globulin, gamma-globulin, immunoglobulins $\mathrm{A}, \mathrm{G}$ and $\mathrm{M}$, and concentrations of transferrin and iron.

A separate scoring from 1 to 4 was used for anamnestic, clinical and laboratory status. From these scores, a final rating was done for overall disease activity, again using a 4-point score.

All questioning and clinical examinations were carried out by one single physician (G. G.) who also did the scoring.

At each patient visit, a first morning urine specimen was provided, shielded from light and frozen at $-20{ }^{\circ} \mathrm{C}$ until analysis for neopterin content. Neopterin determination was performed by a previously described HPLC technique (11). No oxidative pretreatment of the urines was performed, i.e., only native aromatic neopterin was measured. Quantitation was by fluorescence detection at $353 \mathrm{~nm}$ excitation and $438 \mathrm{~nm}$ emission wavelengths. Neopterin concentrations were related to simultaneously deter- mined creatinine (quantitated by its UV absorption at $235 \mathrm{~nm}$ ), and were expressed as $\mu \mathrm{mol}$ neopterin per mol creatinine.

With regard to neopterin measurement, a doubleblind design was used: neither was the neopterin concentration known at the time of the patient visit and the subsequent scoring process, nor was the scoring and, hence, the clinical status, known by the laboratory performing neopterin measurement.

\section{Statistical procedures}

Separate analyses were performed for a) the set of 21 first visits, and b) the whole data set comprising 135 visits. Non-parametric methods were used for univariate evaluations since the distributions were distinctly non-Gaussian. Differences of neopterin concentrations among groups defined by the different scoring variables were assessed by the Kruskal-Wallis H-test, and correlations were tested by Spearman's rank correlation method.

In order to test for an independent value of neopterin as activation marker, we performed a stepwise multiple linear regression analysis on the total data set consisting of 135 records, using the overall activity score as independent variable and the various anamnestic, clinical and laboratory variables, including neopterin, as dependent variables.

The computations were done using programmes BMDP3S and BMDP2R (BMDP Statistical Software Inc., Los Angeles, California, USA, 1987 version).

\section{Results}

Urinary neopterin concentrations showed a positive association with overall disease activity rating. As Figure 1 shows, a significant trend to higher neopterin values with higher grade of overall clinical activity was found for the first visit data set ( 21 records) as well as for the complete data set (135 records).

Table 1 shows the result of statistical analyses of the associations between urinary neopterin concentrations and, separately, anamnestic, clinical and laboratory scores, and overall activity rating. As can be seen, even with the rather small first visit data set, significant associations are commonly seen, both by non-parametric analysis of variance (H-test) and by non-parametric correlation analysis (rank correlation). Essentially the same pattern is seen in Table 2 analysing the association between the Innsbruck index and the different scores. 


\section{FIRST VISIT DATA}

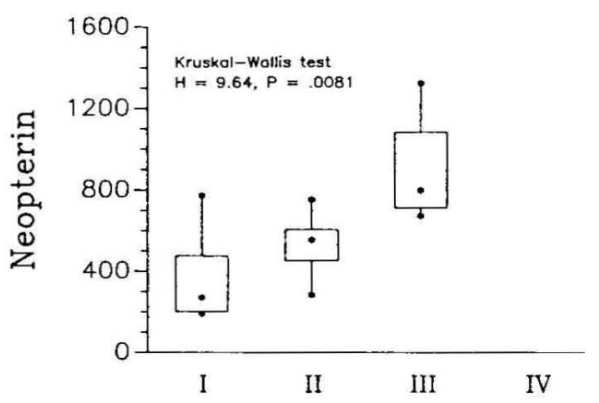

\section{ALL OBSERVATIONS}

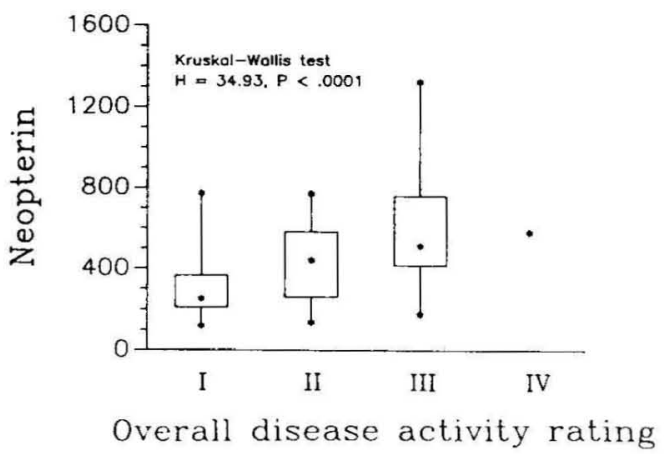

Figure 1. Box-plots showing the distribution of urinary neopterin concentrations in children and adolescents with Crohn's disease.

In the upper part, results are given for the first visit data set (21 records). Patients were classified according to overall disease activity rating: I (= excellent), 8 patients; II (= good), 9 patients; III ( = moderate), 4 patients.

In the lower part, results are given obtained on a total of 135 investigations of the 21 patients. There were 56 investigations with overall disease activity rating I; 51 with II; 27 with III; and 1 with IV $(=$ poor $)$.

In urines of healthy children, the following age-dependent neopterin concentrations were reported (reference 11): 1 to $4 \mathrm{yr}$, mean neopterin $=267(\mathrm{SD} 94) ; 4$ to $7 \mathrm{yr}, 226(76) ; 7$ to $12 \mathrm{yr}$, 181 (73); 12 to $15 \mathrm{yr}, 171$ (73); 15 to $18 \mathrm{yr}, 144$ (65).

Each box-plot shows the median (inside the box), the quartiles (lower and upper limits of the boxes) and the range of the observed values (vertical lines).

Table 3 reports the results of stepwise linear regression analysis using overall clinical activity rating as dependent variable and all the anamnestic, clinical and laboratory data, including neopterin levels, as independent variables. In total, 23 independent variables were analysed: appetite, frequency of stools, frequency of abnormal stools, abdominal mass, abdominal tenderness, extraintestinal lesions, all the 16 laboratory tests listed in the Methods section, and neopterin. Of these variables, a subset of 9 variables was identified to be jointly significant; these are listed in Table 3. The multiple correlation coefficient with this set of variables was 0.90 (R-squared $=0.81$ ), indicating that $81 \%$ of the variation of the dependent variable can be explained by the 9 selected variables.
Table 1. Statistical tests for differences between urinary neopterin concentrations among patient groups defined by anamnestic, clinical or laboratory scores, or by overall disease activity rating ${ }^{a}$ ), and Spearman's rank correlation coefficients

A) First visits (21 records)

\begin{tabular}{|c|c|c|c|c|c|}
\hline \multirow{2}{*}{\multicolumn{2}{|c|}{ Score variable }} & \multicolumn{2}{|c|}{$\begin{array}{l}\text { Kruskal-Wallis } \\
\text { test }\end{array}$} & \multicolumn{2}{|c|}{$\begin{array}{l}\text { Rank } \\
\text { correlation }\end{array}$} \\
\hline & & $\mathrm{H}$ & $\mathrm{P}$ & $\mathrm{R}_{\mathrm{s}}$ & $\mathrm{P}$ \\
\hline Anamnestic & $\left.(12|6| 2 \mid 1)^{b}\right)$ & 8.76 & 0.033 & 0.61 & 0.0064 \\
\hline Clinical & $(5|10| 5 \mid 1)$ & 3.69 & 0.30 & 0.44 & 0.049 \\
\hline Laboratory & (6| $5|8| 2)$ & 7.10 & 0.069 & 0.62 & 0.0056 \\
\hline Overall & $(8|9| 4 \mid 0)$ & 9.64 & 0.0081 & 0.66 & 0.0032 \\
\hline
\end{tabular}

B) All visits (135 records)

\begin{tabular}{llllll}
\hline \multirow{2}{*}{ Score variable } & \multicolumn{3}{l}{$\begin{array}{l}\text { Kruskal-Wallis } \\
\text { test }\end{array}$} & & \multicolumn{2}{l}{$\begin{array}{l}\text { Rank } \\
\text { correlation }\end{array}$} \\
\cline { 2 - 3 } & $\mathrm{H}$ & $\mathrm{P}$ & & $\mathrm{R}_{\mathrm{s}} \mathrm{P}$ \\
\hline Anamnestic & $(86|27| 21 \mid 1)$ & 27.71 & $<0.0001$ & & $0.43<0.0001$ \\
Clinical & $(44|70| 18 \mid 3)$ & 18.87 & 0.0003 & & $0.41<0.0001$ \\
Laboratory & $(43|40| 45 \mid 7)$ & 40.89 & $<0.0001$ & & $0.55<0.0001$ \\
Overall & $(56|51| 27 \mid 1)$ & 34.93 & $<0.0001$ & & $0.53<0.0001$ \\
\hline
\end{tabular}

a) The classifications according to anamnesis, clinical examination, laboratory status and overall disease activity were made using a 4-point score from 1 (excellent) to 4 (bad).

b) Numbers in parentheses show frequencies of records with a certain score for the scoring variable under consideration. For example, $(12|6| 2 \mid 1)$ means 12 patients with score 1,6 with score 2, 2 with score 3 , and 1 with score 4 ).

Table 2. Statistical tests for differences between Innsbruck index values ${ }^{a}$ ) among patient groups defined by anamnestic. clinical or laboratory scores, or by overall disease activity rating and Spearman's rank correlation coefficients

A) First visits (21 records)

\begin{tabular}{|c|c|c|c|c|c|}
\hline \multirow{2}{*}{\multicolumn{2}{|c|}{ Score variable }} & \multicolumn{2}{|c|}{$\begin{array}{l}\text { Kruskal-Wallis } \\
\text { test }\end{array}$} & \multicolumn{2}{|c|}{$\begin{array}{l}\text { Rank } \\
\text { correlation }\end{array}$} \\
\hline & & $\mathrm{H}$ & $\mathrm{P}$ & $\overline{\mathrm{R}_{\mathrm{s}}}$ & $\mathrm{P}$ \\
\hline Anamnestic & $\left(\begin{array}{lll|l}12 & 6 & 2 \mid 1)^{c}\end{array}\right)$ & 6.22 & 0.10 & 0.57 & 0.011 \\
\hline Clinical & $(5|10| 5 \mid 1)$ & 3.95 & 0.27 & 0.37 & 0.098 \\
\hline Laboratory & (6) 5 ( $8 \mid 2$ ) & 7.19 & 0.066 & 0.56 & 0.012 \\
\hline Overall & $\left(\begin{array}{ll|l}8 & 9 & 4\end{array}\right)$ & 6.95 & 0.031 & 0.61 & 0.0064 \\
\hline
\end{tabular}

B) All visits (135 records)

\begin{tabular}{|c|c|c|c|c|c|}
\hline \multirow{2}{*}{\multicolumn{2}{|c|}{ Score variable }} & \multicolumn{2}{|c|}{$\begin{array}{l}\text { Kruskal-Wallis } \\
\text { test }\end{array}$} & \multicolumn{2}{|c|}{$\begin{array}{l}\text { Rank } \\
\text { correlation }\end{array}$} \\
\hline & & $\mathrm{H}$ & $\mathrm{P}$ & $\mathrm{R}_{\mathrm{s}}$ & $\mathrm{P}$ \\
\hline Anamnestic & $(86|27| 21 \mid 1)$ & 32.98 & $<0.0001$ & 0.45 & $<0.0001$ \\
\hline Clinical & $(44|70| 18 \mid 3)$ & 22.23 & 0.0001 & 0.44 & $<0.0001$ \\
\hline Laboratory & $(43|40| 45 \mid 7)$ & 61.97 & $<0.0001$ & 0.69 & $<0.0001$ \\
\hline Overall & $(56|51| 27 \mid 1)$ & 41.41 & $<0.0001$ & 0.59 & $<0.0001$ \\
\hline
\end{tabular}

a) The formula for the Innsbruck Index is given by $\mathrm{STF}+\mathrm{NEO} / 10+5 \times(50-\mathrm{HK})$,

where STF is the weekly frequency of liquid stools, NEO is the urinary neopterin value, and $\mathrm{HK}$ is the hematocrit given in \%. b) The classifications according to anamnesis, clinical examination, laboratory status and overall disease activity were made using a 4-point score from 1 (excellent) to 4 (bad).

c) Numbers in parentheses show frequencies of records with a certain score for the scoring variable under consideration. 
Table 3. Stepwise multiple linear regression analysis relating overall activity rating (dependent variable) to anamnestic, clinical and laboratory findings (independent variables) $)^{\mathrm{a}}$ )

\begin{tabular}{|c|c|c|c|}
\hline Independent variable & $\begin{array}{l}\text { Regression } \\
\text { coefficient }\end{array}$ & $\mathrm{SE}$ & $\left.\mathrm{P}^{\mathrm{b}}\right)$ \\
\hline $\begin{array}{l}\text { Extraintestinal lesions } \\
\text { (number) }\end{array}$ & 0.251 & 0.0489 & $<0.0001$ \\
\hline $\begin{array}{l}\text { Albumin } \\
\left(\begin{array}{l}0 \\
0\end{array}\right)\end{array}$ & -0.0237 & 0.0052 & $<0.0001$ \\
\hline $\begin{array}{l}\text { Abnormal stools } \\
\text { (number per week) }\end{array}$ & 0.0194 & 0.0055 & 0.0004 \\
\hline $\begin{array}{l}\text { Abdominal tenderness } \\
(0=\text { no, } 1=\text { yes })\end{array}$ & 0.288 & 0.0825 & 0.0004 \\
\hline $\begin{array}{l}\text { Thrombocyte count } \\
\text { (number per } \mathrm{nL} \text { ) }\end{array}$ & 0.000838 & 0.000257 & 0.0011 \\
\hline $\begin{array}{l}\text { Serum iron } \\
(\mu \mathrm{g} / \mathrm{dL})\end{array}$ & -0.00360 & 0.0011 & 0.0011 \\
\hline $\begin{array}{l}\text { Urinary neopterin } \\
(\mu \mathrm{mol} / \mathrm{mol} \text { creatinine })\end{array}$ & 0.000477 & 0.000177 & 0.0071 \\
\hline $\begin{array}{l}\mathrm{ESR} \\
(\mathrm{mm} / \mathrm{h})\end{array}$ & 0.00551 & 0.0024 & 0.022 \\
\hline $\begin{array}{l}\text { Appetite } \\
(1=\text { good } \\
2=\text { moderate } \\
3=\text { bad })\end{array}$ & 0.183 & 0.0867 & 0.035 \\
\hline \multicolumn{4}{|c|}{$\begin{array}{l}\text { a) This analysis was performed using the complete data set } \\
\text { (n=135). In the table, only the jointly significant variables ar } \\
\text { included; all other variables were included in the stepwise eval- } \\
\text { uation but did not reach statistical significance. } \\
\text { b) Level of joint significance: the ratio regression coefficient per } \\
\text { standard error is assumed to be asymptotically distributed as } \\
\text { a standard normal deviate. }\end{array}$} \\
\hline
\end{tabular}

\section{Discussion}

Reports regarding immunological phenomena in Crohn's disease are conflicting; one of the major obstacles is that there is no simple way of monitoring local immune processes in the gut. Documentation of $\mathrm{T}$-cell and macrophage activation by a simple and reproducible laboratory assay should give additional information on this disease.

Previous reports have shown that in Crohn's disease in adults measurement of urinary neopterin is of value in assessing inflammatory activity (12), that neopterin may be used for construction of a simple activity index (13), and that a significant correlation exists between neopterin and the number of activated lymphocytes bearing the proliferation marker transferrin receptor (defined by the monoclonal antibody OKT9) (15).

Here, for the first time data are presented obtained on pediatric and juvenile patients with Crohn's disease. The results essentially confirm those obtained in adults. The present study extends previous reports because very extensive anamnestic, clinical and laboratory information was obtained on the patients. Thus, separate analyses for associations between neopterin and anamnestic, clinical, laboratory and overall activity rating were possible.

Statistical evaluation was performed separately for first visit data and for the whole data set comprising also repeat investigations of the same patients. This appeared necessary since analysis of the whole data set alone could have been subject to bias due to statistical dependence of repeat data. As our analyses show, such kind of bias appears to be not very substantial (results of both data sets are essentially similar). This may be a consequence of the fact that the interval between consecutive measurements of the same patient normally exceeded 3 months.

A comment seems necessary to the multivariate analysis shown in Table 3: Firstly, only the full data set was analysed here, because 23 independent variables cannot be reasonably analysed on a data set comprising only 21 patient records. Thus, the abovementioned possible bias due to dependence of repeat visits must be borne in mind. However, other studies on activity markers in Crohn's disease) used multivariate linear regression on data sets containing repeat investigations, too (e.g., 14). Secondly, with the exception of neopterin, all other 22 independent variables, which were included in the analysis, in fact contributed to the overall clinical activity rating, which was the dependent variable in this analysis. Therefore, the null hypothesis is strictly valid only for neopterin; for the other variables the real P-values are likely to be less favorable than the nominal P-values given in the table which are probably inflated. This kind of bias, however, even underscores the value of neopterin as an independent activity marker.

A defect of the present study is certainly the odd distribution of the activity scores: the scores "excellent" and "good" are much more prevalent than the more unfavorable scores. This is a reflection of early diagnoses and, for the whole data set, of repeat visits during long-term follow-up also in periods of quiscence of the disease. Therefore, reliable information on the whole spectrum of the disease is lacking. However, for practical purposes the discrimination in the overrepresented low grades of activity is far more important, so as to get information on the very beginning of relapse when other tests may be normal.

Our study provides further evidence for the involvement of cell-mediated immune activation contributing to inflammatory activity of Crohn's diseases. Neopterin measurement appears to contribute useful in- 
formation regarding monitoring of inflammatory activity of the disease. The information is even enhanced when using the combination of neopterin with stool frequency and hematocrit by means of the Innsbruck index which was derived earlier on data collected from adults with Crohn's disease (13). Importantly, neopterin determination is a non-invasive test; routine testing thus is possible without additional burden for the patient.

\section{Acknowledgement}

We are grateful for evaluating the radiographs to W. Ponhold, F. Ball, H. Hauke and M. A. Lassrich, and for histological examinations of biopsy specimens to P. Schmitz-Moormann. Financial support by the "Jubiläumsfonds" of the Austrian National Bank, project 3127 , is gratefully acknowledged.

\section{References}

1. Sachar, D. B., Ausländer, M. O. \& Walfish, J. S. (1980) Clin. Gastroenterol. 9, 231-257.

2. Kirsner, J. B. \& Shorter, R. G. (1982) N. Engl. J. Med. $306,837-848$.
3. Goodacre, R. L. \& Bienenstock, J. (1982) Gastroenterology 82,653 .

4. Doldi, K., Manger, B., Koch, B., Riemann, J., Hermanek. P. \& Kalden. J. R. (1984) Clin. Exp. Immunol. 55, 655663.

5. Fiocchi, C., Hilfiker, M. L., Youngman, K. R., Doerder, N. C. \& Finke, J. H. (1984) Gastroenterology 86, $734-$ 742 .

6. Kemler, B. J. \& Alpert, E. (1980) Gut 21, 353-359.

7. Sauer, H., Sauer, D., Bendix, U. \& Schumann, B. (1984) Allerg. Immunol. 30, 23-33.

8. MacDermott, R. P. (1986) Hum. Pathol. 17, 219-233.

9. Fuchs, D., Hausen, A., Reibnegger, G.. Werner, E. R., Dierich, M. P. \& Wachter, H. (1988) Immunol. Today 9 $150-155$.

10. Hausen, A., Fuchs, D., Reibnegger, G.. Werner, E. R. \& Wachter, H. (1989) Ptcridines 1, 3-10.

11. Wachter, H., Fuchs, D., Hausen, A., Reibnegger, G. \& Werner, E. R. (1989) Adv. Clin. Chem. 27, 81-141.

12. Prior, C., Bollbach, R., Fuchs, D., Hausen, A., Judmaier, G., Niederwieser, D., Reibnegger, G., Rotthauwe, H. W., Werner, E. R. \& Wachter, H. (1986) Clin. Chim. Acta 155, $11-22$.

13. Reibnegger, G., Bollbach, R., Fuchs, D., Hausen, A., Judmaier, G., Prior, C., Rotthauwe, H. W., Werner, E. R. \& Wachter, H. (1986) Immunobiol. 173, 1-11.

14. Best. W. R., Becktel, J. M., Singleton, J. W. \& Kern, F. (1976) Gastroenterology 70, 439-444.

15. Raedler, A., Studtmann, A., Emskoetter, T., Schulı, K. H., Greten, H.. Fuchs, D. \& Wachter. H. (1987) In: Biochemical and Clinical Aspects of Pteridines, Vol. 5 (Pfleiderer, W., Wachter, H. \& Blair, J. A., eds.) pp. 203-212, Walter de Gruyter, Berlin-New York. 